\title{
Aggregate Shocks and the Relationship between U.S. B usiness Cycle Fluctuations and Export Performance
}

\author{
Prosper Raynold \\ Miami University \\ James A. Dunlevy \\ Miami University
}

\begin{abstract}
In contrast to the preceding literature, we study the relationship between domestic economic activity and export performance within the framework of vector autoregressive representations of the U.S. macroeconomy that expli citly recognize the potential importance of the type of shocks that initiate co-move ments between aggregate activity and export volume. Our results verify that the relationship between aggregate activity and export volume depends upon the type of shock. If the initiating shock is an increase in the relative price of oil or a monetary shock (either contractionary or expansionary), the resulting corre lation between export performance and domestic activity is positive. On the
\end{abstract}

* Correspondence Address: Prosper Ravnold, Associate Professor, Department of Eco- 
other hand, if the initiating shock is a change in government purchases, the correlation is negative. These results are fully consi stent with a broad interpre tation of the capacity pressure hypothesis that allows for the possibility that monetary and other shocks have important effects on the costs of committing resources to the export sector. Our results also suggest that far from being anomalous, the procyclical capacity pressure effect reported in earlier studies is fully consi stent with the capacity pressure hypothesis in that it mer ely reflects the importance of oil price and monetary shocks during the sample periods considered in those studies. (JEL Classification: E32, F 10)

\section{Introduction}

While a growing literature emphasizes the importance of export led growth, in recent years relatively little attention has been paid to the cyclical short-run behavior of exports. In light of the many advances in the empirical study of business cycle phenomena and the wide array of important policy issues that empirical examination of the relationship between fluctuations in aggregate economic activity and exports is likely to clarify, this relative neglect is surprising. Consider the following questions. Do U.S. exports rise during economic downturns and thereby attenuate recessions as was frequently asserted during the last recession? Does the answer to the foregoing question depend upon the type of shock that initiates the slowdown in economic activity? Given that policy makers frequently respond to falling output and employment with expansionary demand side policies, do these positive demand shocks encourage export performance? Some authors 〈see Brock [1991] > argue that export instability may have adverse effects on savings and investment, and thereby, have long-run consequences. Is export instability exacerbated under a policy regime in which policy makers 
previous empirical work on this issue, we employ vector autoregressive (VAR) models of the macroeconomy that emphasize the simultaneous determination and inter dependence of aggregate activity and exports.

As illustrated in studies by M intz [1961, 1967], Ball [1961], and others, the focal point for much of the earlier empirical research on the effects of domestic economic activity on export volume is the capacity pressure hypothesis $(\mathrm{CPH})$. This hypothesis asserts that a ceteris paribus decrease in domestic economic activity leads to a decrease in domestic sales that reduces pressure on productive capacity and increases export volume by allowing for relatively low cost recommitment of excess capacity to the foreign market. Given the hypothesized inverse relationship between capacity pressure and export volume, tests of the $\mathrm{CPH}$ have typically focused on the empirical relation between some measure or proxy for capacity pressure and export volume. Since deviation-from-trend output is frequently used as a proxy for capacity pressure, the results of these tests are also considered to be informative about the relation between business cycle movements and exports.

Using single equation methods and British data, Ball, Eaton, and Steuer [1966], Artus [1970, 1973], and Winters [1974] report an inverse relationship between capacity pressure and export performance. However, their results require careful scrutiny since the empirical models they employed did not adequately account for the simultaneous nature of the relationship between export volume and relevant prices.

In recognition of these difficulties, Dunlevy [1980] employed a simultaneous equations, supply-demand framework of the export market to test the $\mathrm{CPH}$ for the U nited States and the U nited Kingdom. With capacity pressure viewed as an export supply phenomenon and measured as deviation-fromtrend output, Dunlevy found that export supply moved, ceteris paribus, in a procyclical fashion. In response to this provocative result, Haynes and Stone 
in developing countries, Faini [1994] challenged the profession to provide both "theoretical and statistical explanation" ( $p 83$ footnote 2 ) of the seemingly anomalous finding that capacity utilization has positive effects on exports. ${ }^{1}$

Our review of the literature in this area lead us to the conclusion that it is dominated by the presumption that the shocks which typically buffet the macroeconomy affect domestic output and capacity pressure by changing aggregate demand. This presumption is well illustrated by the typical choice of proxies for capacity pressure. Dunlevy and Haynes and Stone, for instance, use transformations of domestic economic activity as proxies for capacity pressure. However, the efficacy of these transformations of industrial production and real GNP as proxies for capacity pressure depends upon the nature of the innovations that initiate business cycle fluctuations. If aggregate demand innovations are the primary source of business cycle fluctuations, variation in domestic economic activity will be consistently and positively related to capacity pressure and measures based on deviation-fromtrend industrial production or real GNP will be effective proxies for capacity pressure. Under this scenario, evidence in support of the $\mathrm{CPH}$ may be interpreted as supportive of the view that there is an inverse relationship between domestic activity and export volume. However, if business cycle fluctuations are typically initiated by both aggregate demand and aggregate supply innovations, the direction of the relationship between capacity pressure and changes in domestic activity will not be consistently positive. In particular, unlike an increase in domestic activity due to a positive demand shock, a ceteris paribus favorable supply shock increases output but decreases the pressure on capacity. Consequently, if both demand and supply shocks are important explanators of business cycle fluctuations, measures of domestic activity such as deviation-from-trend industrial production or real GNP will 
nation" for the seemingly anomalous finding that capacity pressure has positive effects on exports is likely to be uncovered by closer examination of the nature of the shocks that initiate business cycle fluctuations and that generate correlations between exports and domestic activity. In pursuit of this explanation it is important to consider the conditions under which a given shock will generate the traditionally expected negative relationship between capacity utilization and exports. Under the capacity pressure hypothesis, in order for a shock to generate a negative relationship or correlation between domestic activity and the volume of exports, the shock must first alter the level of excess capacity. Second, given the change in the pressure on capacity, the volume of exports would move in the opposite direction if firms are able to recommit resources to the foreign market at relatively low costs. For example, an increase in the federal funds rate (i.e. a monetary tightening) is typically thought to affect domestic economic activity by reducing aggregate demand which leads to an increase in excess capacity. As a result, export volume increases as firms recommit resources to the export sector. However, if the increase in the federal funds rate also increases the costs of maintaining initial levels of exports and of recommitting resources to the foreign market, the increase in excess capacity could actually be associated with a decline in the volume of exports. M ore generally, a given shock will lead to the presumed negative relationship between exports and capacity utilization or domestic output if it affects capacity utilization through its effect on aggregate demand and if it does not have material adverse effects on the costs of recommitting resources to the foreign market.

This paper addresses the issues raised above by evaluating the relationship between the domestic business cycle and export volume within vector autoregressive representations of the U.S. macroeconomy. All variables are treated as jointly determined in order to capture the simultaneous nature of 
ment purchases and in monetary policy - that are traditionally viewed as having their primary impact on aggregate demand - and changes in the relative price of oil that are frequently associated with aggregate supply. ${ }^{3}$ Our examination of the responses of domestic activity and export volume to these shocks indicates that, on average, increases in the relative price of oil and monetary policy innovations generate a positive relationship between U.S. exports and U.S. industrial production while changes in government purchases generate a negative relation. To the extent that monetary and oil price shocks were the principal initiators of business cycle fluctuations during the sample period considered in the Dunlevy and Haynes - Stone studies, our results suggest that the positive relationship they uncovered reflects the type of shocks that buffeted the economy during their sample period.

Our model also permits an evaluation of the impact of other variables on U.S. export performance. Virtually all commentators believe that foreign economic activity is a key determinant of foreign demand, and is therefore a primary explanator of U.S. export volume. 〈see M intz [1961], p. 15 and M intz [1967] passim >. Similarly, many analysts believe that U.S. exports are inversely related to the price of U.S. exports and positively correlated with the level of foreign prices. While these relationships are not the focus of this study, it is instructive to note that the empirical regularities uncovered in this paper are consistent with these views.

The empirical models we employed are described in section II. Section III is devoted to a discussion of the empirical results and our conclusions are summarized in section IV.

\section{Model Specification and Data}

As indicated above, our primary purpose is to uncover and interpret 
the flow of U.S. exports. In pursuit of this objective, we specify and estimate a vector autoregressive (VAR) model using quarterly data from 1959:ii to 1987:iv. ${ }^{4}$ The VAR model treats all variables as jointly determined and is therefore consistent with Goldstein and Kahn 〈[1985], p. 1072〉 who note that

"simultaneity is not a problem that can be dealt with by assump-

tion, par ticularly in relation to exports."

and advocate use of vector autoregressive techniques to study the relations under consideration in this paper.

\section{A. The Basic VAR Model}

Let $Z_{t}$ represent an $n \times 1$ vector of variables that adequately capture the macroeconomic context within which any relationship between aggregate economic activity and the volume of exports arises. $Z_{t}$ is assumed to evolve according to the following vector autoregressive process.

$$
Z_{t}=A_{0}+A_{1} Z_{t-1}+A_{2} Z_{t-2}+A_{3} Z_{t-3}+\ldots+A_{k} Z_{t-k}+u_{t}
$$

in which the $A_{i}{ }^{\prime}$ s for $i=0,1,2, \ldots, k$ are coefficient matrices and $u_{t}$ is an $n \times 1$ vector of serially uncorrelated disturbances. Contemporaneous values of the variables in $Z_{\mathrm{t}}$ do not appear on the right hand side of (1); therefore, any contemporaneous correlation among the model's variables is reflected in the VAR residuals (i.e. $u_{t}$ ). Since this makes it difficult to attach economic interpretation to the effects of impulses to the elements of $u_{t}$ on the model's variables, it is imperative that we work with or thogonalized innovations.

Under the assumption that the economy is driven by $a n n \times 1$ vector of serially uncor related fundamental shocks $\left(\varepsilon_{t}\right)$ with covariance matrix equal to the identity matrix, there is a matrix $C$ that is a unique $n \times n$ lower triangu- 


$$
C C^{\prime}=E\left[u_{t} u_{t}^{\prime}\right] .
$$

$M$ oreover, $u_{t}$ may be specified as a linear function of the fundamental shocks, as follows:

$$
\mathrm{u}_{\mathrm{t}}=\mathrm{C} \varepsilon_{\mathrm{t}} \text {. }
$$

In general, estimates of the $A_{i}$ 's are obtained by using ordinary least squares to estimate ( 1 ) equation by equation. Since $C$ is uniquely determined by the relationship summarized in (2), (3) can be used to derive the economically meaningful fundamental shocks $\left(\varepsilon_{t}\right)$. Consequently, (1) and (3) may be used to calculate the impulse responses of any variable in $Z_{t}$ to a unit impulse in any of the elements in $\varepsilon_{t}$.

It is well known that the decomposition described above imposes a recursive structure on the contemporaneous relations among the model's variables. For example, placing our monetary policy indicator sixth in the ordering for the decomposition, imposes the restriction that impulses to the five variables that precede it, elicit contemporaneous or within-quarter effects from monetary policy but that monetary policy impulses have no withinquarter effects on these variables. As a consequence, the manner in which the elements of $u_{t}$ are ordered for the decomposition is of substantial import.

The analysis that follows is based on two ten-variable VAR models. Four standard international trade variables are included in both models. These are; the volume of U.S. exports (USEX), a measure of world economic activity (WEA), a measure of the price of world exports (PWEX), and a measure of the price of U.S. exports (PUEX). To capture the state of the macroeconomy, U.S. economic activity as measured by the index of industrial production (USIP) and the producer price index for U.S. manufactured goods (PPIUS) are included in both models. M ost authors explicitly consider mea- 
In our view, examination of the empirical relation between domestic aggregate economic activity and USEX must be conducted within empirical models that explicitly account for the fundamental forces that generate this relationship. For example, if both policy and nonpolicy innovations have effects on exports that are independent of their effects on aggregate activity, failure to explicitly include measures of these variables in the VAR model would result in omitted variables problems of the type articulated in Lutkephol [1982]. Moreover, this problem is exacerbated if the effect of variation in economic activity on exports depends upon the nature of the shocks that generate movements in aggregate activity. In light of these considerations, we include an oil price measure (POIL), real government purchases (GPUR), and an indicator of monetary policy in both models.

Our inclusion of an oil price measure in both models is consistent with empirical regularities reported by Hamilton [1983] which show that major downturns in U.S. economic activity were typically preceded by exogenous increases in the price of oil. In addition, while there is some disagreement about the precise mechanism via which increases in the price of oil affect the real economy, oil price increases and monetary policy are widely believed to be strong competitors for the dubious distinction of being the key initiating factor in postwar U.S. recessions. Consideration of the mechanisms via which oil price shocks affect the real economy highlight the importance of including both an oil price measure and a monetary policy indicator in the model. In particular, Bernanke, Gertler, and Watson [1997] and Hamilton [1996b] show that increases in the price of oil typically induce the Federal Reserve to tighten monetary policy. In addition, Bernanke, Gertler, and Watson [1997] find that this endogenous response of monetary policy accounts for most of the contractionary effects of adverse oil price shocks on the real economy. Given the implications for the Federal 
Given our interest in accounting for the effects of policy shocks on the relationship between U.S. exports and aggregate economic activity, we deemed it important to include GPUR as a fiscal measure that is potentially informative about the aforementioned relations. This is consistent with the many theoretical approaches that attribute an important role to real government purchases in the determination of aggregate economic activity. ${ }^{7}$

$M$ onetary policy is the sum of an endogenous component that reflects the Federal Reserve's reaction function and an exogenous component that is independent of the state of the macroeconomy. Since the measured response of economic variables to endogenous monetary policy reflects both the effects of the policy response and the economic conditions to which the monetary authority is responding, economically meaningful interpretations can only be attached to the measured responses to the exogenous component of monetary policy. Consequently, the proper identification of exogenous monetary policy is of substantial import. For example, Gordon and Leeper [1994] and Strongin [1995] show that the wellknown liquidity and price puzzles associated with monetary policy were largely the result of improperly identified monetary policy shocks. Given the importance of correctly identifying monetary policy shocks, we employ two different approaches to identifying monetary policy. While these approaches lead to important differences between the VAR models we specify, our results are largely robust to the manner in which we identify

a large number of variables (ten), our concerns about parsimony outweighed any concerns about lack of symmetry or omitted variable problems. Second, the failure of large reductions in the price of oil in the mid-1980's to lead an economic expansion raises important questions about the ability of decreases in the relative price of oil to explain economic activity. In fact, M ork [1989] examined the effects of both negative

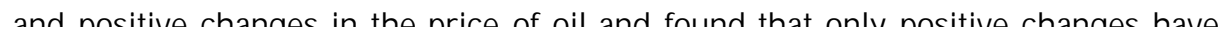


exogenous monetary policy.

\section{B. Identifying Monetary Policy Shocks}

In M odel I, we follow Bernanke and Blinder [1992], Christiano, Eichenbaum, and Evans [1996, 1997] and use the federal funds rate as the indicator of monetary policy. However, given the distinct possibility that the Federal Reserve reacts within the quarter to changes in the state of the macroeconomy, the derivation of economically meaningful results dictates that we identify the portion of variation in FFR that is purely reflective of exogenous monetary policy. In pursuit of this objective, we employed the approach described in Christiano, Eichenbaum, and Evans [1996, 1997] and imbed an interest rate smoothing rule within the structure of the VAR model summarized in equations ( 1 ) and ( 3 ). The rule we employ is given by

$$
\mathrm{FFR}_{\mathrm{t}}=\psi\left(\mathrm{X}_{\mathrm{t}}\right)+\varepsilon_{\mathrm{ft}} ;
$$

where FFR is the federal funds rate, $\psi$ is a linear function, and $X_{t}$ is a vector of macrovariables that summarizes the information set available to the Federal Reserve at the time when it sets its policy instrument. $X_{t}$ includes contemporaneous and lagged values of the subset of the variables in $Z_{t}$ to which the monetary authority is assumed to react within the quarter and only lagged values of the remaining variables in $\mathrm{Z}_{\mathrm{t}}$. Christiano, Eichenbaum, and Evans $[1996,1997]$ assume that innovations in the contemporaneous variables in $X_{t}$ elicit within quarter monetary policy responses but that these variables do not respond to monetary policy within the quarter. This recursiveness assumption implies that $\varepsilon_{\mathrm{ft}}$ is orthorgonal to the elements of $X_{t}$ and justifies OLS estimation of (4) and interpreting $\varepsilon_{\mathrm{ft}}$ as the monetary policy shock. Consequently, the impulse responses of a variable to a monetary 
the decomposition described in the previous section.

For the purposes of this paper, $X_{t}$ includes the contemporaneous and lagged values of POIL, GPUR, USIP, PPIUS, and an index of sensitive commodity prices (PCOM) (in that order) and only the lagged values of FFR, USEXP, WEA, PWEXP, and PUSEXP. As noted earlier, the recursiveness assumption amounts to the restriction that the $F$ ederal Reserve responds to innovations in POIL, GPUR, USIP, PPIUS, and PCOM within the quarter but has no contemporaneous effect on these variables. Consistent with this specification, $Z_{t}$ is comprised of the following variables in the order employed for the decomposition: POIL, GPUR, USIP, PPIUS, PCOM, FFR, USEXP, WEA, PWEXP, and PUSEXP.

Our inclusion of contemporaneous values of POIL in $X_{t}$ is consistent with Hamilton [1983] who carefully demonstrates that oil price changes are largely exogenous events associated with political and other events. It is also consistent with Bernanke, Gertler, and Watson [1997] who also include contemporaneous values of an oil price variable in their version of $X_{t}$ and demonstrate that the federal funds rate responds positively to increases in the price of oil. Hamilton [1996b] also reports a similar finding. Finally, POIL is ordered ahead of USIP and PPIUS under the reasonable presumption that increases in the relative price of oil affect these variables within the quarter.

To the extent that GPUR may be interpreted as an indicator of fiscal poli$c y$, our inclusion of contemporaneous values of GPUR in $X_{t}$ reflects the view that monetary policy responds within the quarter to innovations in fiscal policy. However, given the relatively long lags that are typically associated with fiscal policy, it is very unlikely that GPUR responds to monetary policy within the quarter.

Our inclusion of contemporaneous values of USIP, PPIUS, and PCOM in 
tains information that the Fed has about future inflation that is not captured by the other variables in the model. ${ }^{89}$

To check the robustness of the results to our choice of the federal funds rate as the indicator of monetary policy, we estimate a second model in which nonbor rowed reserves is taken to be the indicator of monetary policy. In addition, we use the approach described in Strongin [1995] to identify exogenous monetary policy.

Strongin's approach is based on the observation that forecast innovations in nonborrowed reserves reflect both independent monetary policy and the Federal Reserves' accommodation of innovations in the demand for total reserves. Strongin assumes that the level of total reserves is largely determined by the Federal Reserves' short-run accommodation of the demand for total reserves and that true monetary policy innovations do not have short run effects on total reserves. This leads him to the plausible conclusion that independent monetary policy is reflected in the mix of borrowed and nonborrowed reserves that the Federal Reserve uses to meet increases in the demand for total reserves. Given these assumptions, he argues that the contemporaneous relations among forecast innovations in nonborrowed reserves, forecast innovations in total reserves, and exogenous monetary policy are adequately captured by the following equation

$$
n \mathrm{nr}_{\mathrm{t}}=\phi \mathrm{tr}_{\mathrm{t}}+\mathrm{v}_{\mathrm{st}}
$$

in which $n b r_{t}$ is the forecast innovation in nonbor rowed reserves, $\operatorname{tr}_{t}$ is the

8. Bernanke, Gertler, and Watson [1997] note that the commodity price index (i.e. PCOM ) apparently excluded oil and other energy prices for most of its history. However, an oil price was added to the index in 1987. Since our sample ends in 1987, we do not expect that our results will be materially affected.

9. In general, confidence in the appropriateness of the assumption that PCOM does not

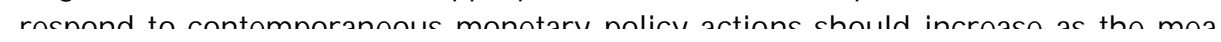


forecast innovation in total reserves, and $v_{\text {st }}$ is the fraction of the forecast innovation in nonborrowed reserves that is the pure policy shock.

The restrictions summarized in (5) imply that innovations in total reserves have important contemporaneous effects on nonborrowed reserves but that innovations in nonborrowed reserves have no contemporaneous effects on total reserves. Consequently, and as Strongin [1995] demonstrates, the restrictions implied in (5) are easily imposed on the VAR structure described in (1) and (2) by including total reserves and nonborrowed reserves in $Z_{t}$ and placing total reserves ahead of nonborrowed reserves for the decomposition.

To implement the Strongin approach, we replace PCOM and FFR with total reserves (TR) and nonborrowed reserves (NBR) where we have normalized both variables with a 36-month moving average of total reserves. The resulting VAR model (M odel II) is comprised of the following variables in the order employed for the decomposition. These are: POIL, GPUR, USIP, PPIUS, TR, NBR, USEX, WEA, PWEX, and PUEX. ${ }^{10}$

In choosing the number of variables that entered the VAR model, we were acutely aware of the tradeoff between parsimony on the one hand and the risk of omitted variables on the other. To some extent our decision to include ten variables in each of the VAR models specified above, suggests that we have attached greater weight to the risk of omitted variables. To examine the robustness of our results to model size, we estimated the following VAR models and calculated impulse responses, which we report in Figure 4. For these models $Z_{t}$ is defined as: (variables are in the order employed for the decomposition) (1) POIL, USIP, PPIUS, USEX, WEA,

10. Throughout this paper the international variables (i.e. USEX, WEA, PWEX, and

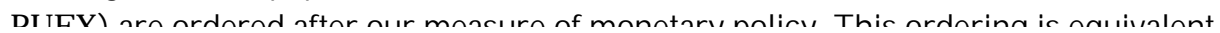


PWEX, PUEX; (2) GPUR, USIP, PPIUS, USEX, WEA, PWEX, PUEX; (3) USIP PPIUS, PCOM, FFR, USEX, WEA, PWEX, PUEX; (4) USIP PPIUS, TR, NBR, USEX, WEA, PWEX, PUEX.

\section{Data}

The empirical counterparts to the model's variables are as follows. USEX is measured by the quantum index of U.S. exports. Consistent with studies by Culem [1987], Dunlevy, and others, world economic activity is proxied by "effective" world purchasing power measured as the real value of world exports minus U.S. imports. Alternative measures of world activity such as trade weighted sums of national GDPs can be found in the literature. However, in contrast to these alternatives, the measure employed here reflects variations in openness of the world trading system. Industrial production is used to measure U.S. economic activity instead of real GNP since the trade data we employ is mostly reflective of trade in goods. PUEX and PWEX are, respectively, the unit values of U.S. and world exports. The data for USEX, WEA, PUEX, and PWEX come from the International Monetary Fund's International Financial Statistics.

In addition to these variables, we calculated changes in the relative price of oil as the difference between the rate of change of the producer price index for crude oil and the rate of change of the producer price index for all commodities. Following Mork [1989], Dotsey and Reid [1992], and Bernanke, Gertler, and Watson [1997] POIL is constructed by setting all negative values of the resulting series equal to zero. PPIUS is represented by the producer price index for manufactured goods. ${ }^{11}$ Our choice of the PPI for manufactured goods over other measures such as the PPI for all commodities or the $\mathrm{CPI}$ reflects the view that the mix of goods measured in 
commodity prices. Our measures of total reserves (TR) and nonborrowed reserves (NBR) are based, respectively, on the Citibase series FMRRA and FMRNBA which are both adjusted for seasonality and for reserve requirement changes. Following Bernanke and M ihov [1995] both series are normalized with a 36-month moving average of total reserves. The federal funds rate, industrial production, the various producer price indices, and real government purchases come from Citibase. Finally, as noted previously, we employ quarterly data from 1959:II to 1987:IV.

Augmented Dickey-Fuller tests for first order unit roots together with Engle-Yoo [1987] and Hansen [1990] tests for cointegration suggested that with the exception POIL, the first differences of the variables of interest should be used in specifying and estimating the VAR models. Consequently, the models were specified and estimated with the first differences of $T R$ and NBR, the first differences of the log of all other variables except POIL and FFR which are entered in their levels. ${ }^{12}$

Akaike's information criterion (AIC) was used to specify the VAR models' lag length and indicated a lag length of $8 .{ }^{13}$ After accounting for observations lost due to normalization of TR and NBR, differencing, and the maximum lag of eight used in the AIC test, the model was estimated for the period 1964:II to 1987:IV. Ljung-B ox Q-statistics suggested no need for concern about serial correlation in the equations' residuals.

\section{Empirical Results}

Cumulative IRFs together with their one standard deviation confidence

12. While the Engle-Yoo and J ohansen [1988] tests are widely used to test for cointegration, Hansen [1990] has shown that these tests suffer from substantial loss of power

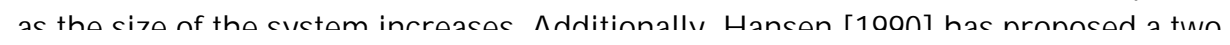


bands are presented in Figures 1 through $4 .{ }^{14}$ In addition, variance decompositions (VDCs) of exports and industrial production together with their standard er rors are presented in Tables $1 \mathrm{~A}$ and $1 \mathrm{~B}$ for $\mathrm{M}$ odel I, and Tables $2 \mathrm{~A}$ and $2 \mathrm{~B}$ for $\mathrm{M}$ odel II.

\section{A. Variance Decompositions}

Tables $1 \mathrm{~A}$ and $1 \mathrm{~B}$ indicate that the fraction of the forecast error variation in USIP explained by innovations in POIL is substantial, but significantly less than the percent of the variation in USEX explained by POIL. Examination of VDCs based on M odel II reported in Tables 2A and 2B suggest that they are very consistent with the results based on M odel I. These results are supportive of the view that increases in the relative price of oil have important effects on both USIP and USEX. In addition, they are not inconsistent with Hamilton [1983] and others who attribute an important role to oil price increases as an initiator of fluctuations in aggregate economic activity.

The VDCs based on both models indicate that GPUR explains a moderate percent of the FEV in USIP. In addition, the fraction of the FEV in USEX explained by GPUR at various horizons is moderate to small and the accompanying standard errors suggest that the point estimates are relatively imprecisely estimated. Overall, these results suggest that GPUR played a moderately important role as an explanator of business cycle fluctuations during our sample. This conclusion is not inconsistent with the views of many economists who attribute an important but not dominant role to innovations in government purchases.

As noted previously, the federal funds rate is taken to be the monetary policy indicator in M odel I, and exogenous monetary policy is identified 
Table 1A

Variance Decomposition of U.S. Industrial Production (Model I)

(Ordering: POIL, GPUR, USIP, PPIUS, PCOM , FFR, USEX, WEA, PWEX, PUEX)

\begin{tabular}{|c|r|c|c|c|c|c|c|c|c|c|}
\hline FH & POIL & GPUR & USIP & PPIUS & PCOM & FFR & USEX & WEA & PWEX & PUEX \\
\hline \multirow{2}{*}{4} & 1.43 & 6.67 & 42.76 & 3.68 & 13 & 11.35 & 1.91 & 1.8 & 7.79 & 9.6 \\
& 2.14 & 2.66 & 5.48 & 2.63 & 6.56 & 4.34 & 2.07 & 2.47 & 1.92 & 0.98 \\
\hline \multirow{2}{*}{8} & 4.93 & 4.85 & 24.54 & 7.93 & 30.01 & 9.13 & 3.18 & 1.12 & 8.7 & 5.63 \\
& 3.19 & 1.96 & 4.48 & 3.26 & 6.21 & 3.07 & 2.22 & 3.27 & 3.44 & 0.64 \\
\hline \multirow{2}{*}{12} & 11.41 & 6.04 & 22.67 & 8.6 & 20.38 & 7.18 & 4.04 & 1.67 & 10.26 & 7.75 \\
& 4.58 & 2.84 & 3.87 & 3.09 & 5.19 & 3.23 & 2.64 & 3.46 & 4.25 & 0.87 \\
\hline \multirow{2}{*}{16} & 11.46 & 7.83 & 19.24 & 7.67 & 20.32 & 5.97 & 6.55 & 3.64 & 10.49 & 6.81 \\
& 4.24 & 2.75 & 3.56 & 3 & 5.14 & 2.9 & 3.05 & 4.42 & 3.96 & 0.81 \\
\hline
\end{tabular}

Notes: The column labeled $\mathrm{FH}$ is the forecast horizon in quarters. For each forecast horizon, the numbers in the upper row are the point estimates while those in smaller print in the lower rows are the corresponding standard errors.

Table 1B

Variance Decomposition of U.S. Exports (Model I) ${ }^{1}$

(Ordering: POIL, GPUR, USIP, PPIUS, PCOM, FFR, USEX, WEA, PWEX, PUEX)

\begin{tabular}{|c|r|c|c|c|c|c|c|c|c|c|}
\hline FH & POIL & GPUR & USIP & PPIUS & PCOM & FFR & USEX & WEA & PWEX & PUEX \\
\hline \multirow{2}{*}{4} & 14.69 & 5.89 & 2.33 & 3.66 & 2.24 & 1.68 & 50.34 & 2.21 & 10 & 6.98 \\
& 4.27 & 2.99 & 4.51 & 2.98 & 5.36 & 1.76 & 6.17 & 4.01 & 4.5 & 0.74 \\
\hline \multirow{2}{*}{8} & 21.24 & 6.01 & 2.64 & 5.66 & 2.39 & 2.61 & 33.79 & 5.35 & 8.52 & 11.79 \\
& 6.81 & 3.3 & 4.25 & 3.56 & 5.13 & 2.24 & 4.96 & 3.3 & 3.34 & 1.25 \\
\hline \multirow{2}{*}{12} & 19.88 & 5.98 & 3.88 & 6.14 & 7.86 & 3.79 & 27.86 & 5.68 & 8.32 & 10.61 \\
& 5.68 & 3.44 & 3.69 & 4.03 & 6.68 & 1.95 & 5.01 & 3.1 & 3.92 & 1.02 \\
\hline \multirow{2}{*}{16} & 17.45 & 7.29 & 6.58 & 5.5 & 8.15 & 3.61 & 26.21 & 5.56 & 10.04 & 9.62 \\
& 5.83 & 4.06 & 4.58 & 4.43 & 5.69 & 2 & 4.89 & 3.48 & 3.94 & 0.99 \\
\hline
\end{tabular}


Table 2A

Variance Decomposition of U.S. Industrial Production (Model II) ${ }^{1}$

(Ordering: POIL, GPUR, USIP, PPIUS, PCOM, FFR, USEX, WEA, PWEX, PUEX)

\begin{tabular}{|c|c|c|c|c|c|c|c|c|c|c|}
\hline FH & POIL & GPUR & USIP & PPIUS & PCOM & FFR & USEX & WEA & PWEX & PUEX \\
\hline \multirow{2}{*}{4} & 7.1 & 2.89 & 59.32 & 6.29 & 4.87 & 1.84 & 2.94 & 5.2 & 4.04 & 5.5 \\
& 4.8 & 2.53 & 6.81 & 3.69 & 2.61 & 2.48 & 2.87 & 2.91 & 3.85 & 2.13 \\
\hline \multirow{2}{*}{8} & 8.14 & 8.11 & 38.67 & 9.69 & 12.55 & 6.12 & 2.8 & 3.02 & 3.67 & 7.24 \\
& 5.47 & 3.83 & 5.27 & 3.3 & 5.92 & 3.45 & 2.27 & 1.78 & 2.64 & 1.56 \\
\hline \multirow{2}{*}{12} & 10.08 & 8.09 & 31.01 & 8.08 & 10.77 & 13.93 & 3.09 & 2.16 & 4.56 & 8.24 \\
& 4.9 & 5.52 & 4.59 & 2.8 & 5.51 & 4.18 & 2.02 & 1.37 & 2.49 & 1.81 \\
\hline \multirow{2}{*}{16} & 7.67 & 12.16 & 21.37 & 6 & 13.68 & 21.55 & 5.06 & 1.74 & 4.59 & 6.18 \\
& 5.15 & 4.93 & 4.96 & 3.54 & 6.01 & 4.36 & 2.73 & I.S & 2.84 & 1.65 \\
\hline
\end{tabular}

Notes: 1 . The column labeled $\mathrm{FH}$ is the forecast horizon in quarters. For each forecast horizon, the numbers in the upper row are the point estimates while those in smaller print in the lower rows are the corresponding standard errors.

Table 2B

Variance Decomposition of U.S. Exports (Model II) ${ }^{1}$

(Ordering: POIL, GPUR, USIP, PPIUS, PCOM, FFR, USEX, WEA, PWEX, PUEX)

\begin{tabular}{|c|c|c|c|c|c|c|c|c|c|c|}
\hline FH & POIL & GPUR & USIP & PPIUS & PCOM & FFR & USEX & WEA & PWEX & PUEX \\
\hline \multirow{2}{*}{4} & 3.1 & 6.32 & 6.28 & 9.59 & 3.19 & 7.54 & 50.52 & 1.99 & 3.13 & 8.34 \\
& 3.23 & 5.63 & 2.76 & 5.33 & 4.98 & 3.62 & 6.46 & 1.32 & 1.45 & 1.42 \\
\hline \multirow{2}{*}{8} & 8.01 & 7.19 & 9.92 & 7.12 & 10.56 & 7.36 & 25.05 & 9.64 & 3.3 & 11.85 \\
& 5.68 & 4.19 & 4.07 & 4.95 & 5.84 & 3.19 & 4.6 & 3.26 & 1.29 & 1.82 \\
\hline \multirow{2}{*}{12} & 12.11 & 6.9 & 10.2 & 8.68 & 15.95 & 6.23 & 18.89 & 7.65 & 4.12 & 9.27 \\
& 7.04 & 4.63 & 3.86 & 4.18 & 5.31 & 2.85 & 3.66 & 2.47 & 1.28 & 1.51 \\
\hline \multirow{2}{*}{16} & 17.5 & 5.75 & 9.14 & 9.82 & 15.63 & 5.57 & 15.74 & 8.14 & 3.84 & 8.88 \\
& 7.12 & 4.29 & 3.99 & 4.08 & 5.23 & 3.17 & 3.21 & 2.33 & 1.32 & 1.33 \\
\hline
\end{tabular}


Our indicator of monetary policy in Model II is nonborrowed reserves and monetary policy shocks are identified using the methods described in Strongin [1995]. The variance decompositions reported in Tables 2A and 2B show that NBR explained relatively more of the FEVS in both USIP and USEX than FFR did in Model I. However, the results are broadly similar in that both M odels suggest that monetary policy shocks have relatively more impor tant effects on USIP than on USEX.16

Finally, to evaluate the importance of including WEA, PWEX, and PUEX in the model, we examine their ability to explain variation in USEX. The VDCs based on M odel I in Table 1B suggest that all three variables explain significant (i.e. as indicated by standard errors that are small relative to the point estimates) fractions of the FEV in USEX, although PWEX and PUEX explain relatively more of the FEV in USEX than WEA. In addition, the VDCs based on M odel II in Table $2 B$ are also consistent with the view that PWEX, PUEX, and WEA are important explanators of movements in USEX. Overall, these results bolster our confidence in the empirical model's ability to uncover the true economic relations embedded in the data.

\section{B. Impulse Responses}

Panel A of Figure 1 (based on M odel I) indicates that a one standard deviation shock to world economic activity (WEA) has an immediate, significantly positive effect on USEX. In addition, examination of Panel $B$ indicates that (with the exception of an initial negative impact) a shock to the price of world exports (PWEX) elicits significantly positive effects from USEX for most horizons. Finally, panel C illustrates that U.S. export performance is negatively affected by a shock to the price of U.S. exports (PUEX). Overall, these results are consistent with widely held beliefs about the effects of 


\section{Figure 1}

Impulse Responses of USEX to Int'I Variables
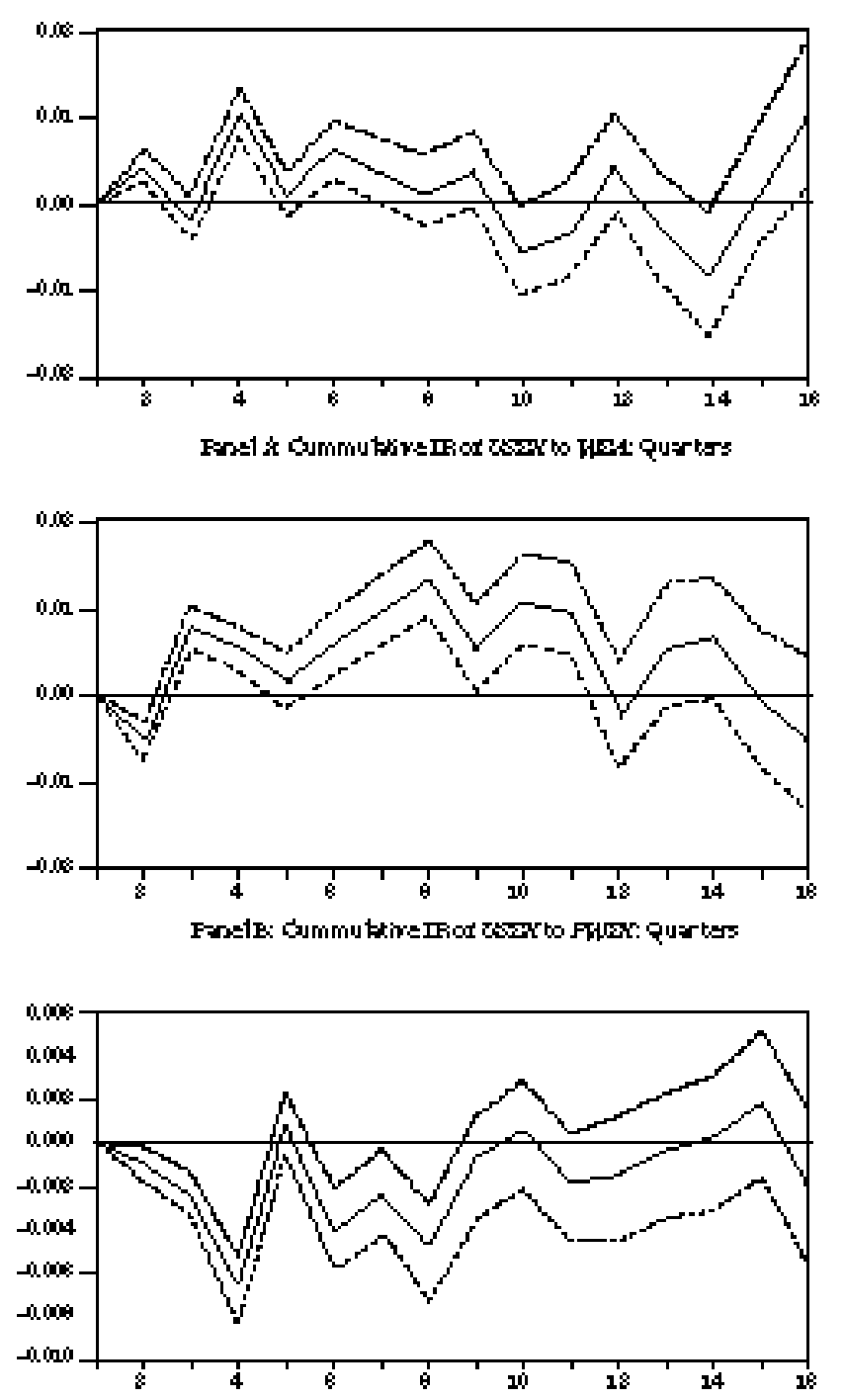
because of co-movements initiated by nonpolicy and/ or policy shocks from those that reflect the response of USEX to shocks to USIP or vice versa. Comovements between exports and domestic economic activity arise largely because nonpolicy and/ or policy shocks elicit responses from both USEX and USIP. F or example, if the direction of the effects of a monetary shock on USIP and USEX are of opposite sign, the implied relation between USEX and USIP is interpreted as negative. Such a relation is separate from the relation that arises because of a USIP shock that is fundamental in the sense that it is uncorrelated with any other shocks. To the extent that business cycle fluctuations are systematic responses to various exogenous shocks, we view the co-movements between USEX and USIP as more informative about the relationship between the domestic business cycle and export performance.

The impulse responses reported in panel A of Figure 2 indicate that a one standard deviation shock to POIL has significantly positive effects on USEX around the third quarter after the shock, followed by significantly negative effects over most of the next three years. ${ }^{17}$ In panel $B$, the shock to POIL elicits positive responses from USIP for the first 5 quarters followed by negative responses over the next 4 quarters and then by positive responses. The rather ambiguous sign of the responses and the fact that the point estimates fall within the one standard deviation bands make it difficult to interpret the overall direction of the implied correlation between USEX and USIP. However, the conclusion that the cor relation is weakly positive seems reasonable. Examination of the impulse responses reported in panels $A$ and $B$ of Figure 3, (based on M odel II) provide clearer indication that the implied relationship between USEX and USIP is positive. In addition, the impulse responses of USEX and USIP to a one standard deviation shock to POIL based on a seven-variable model comprised of POIL, USIP, PPIUS, 


\section{Figure 2}

Impulse Responses of USEX and USIP
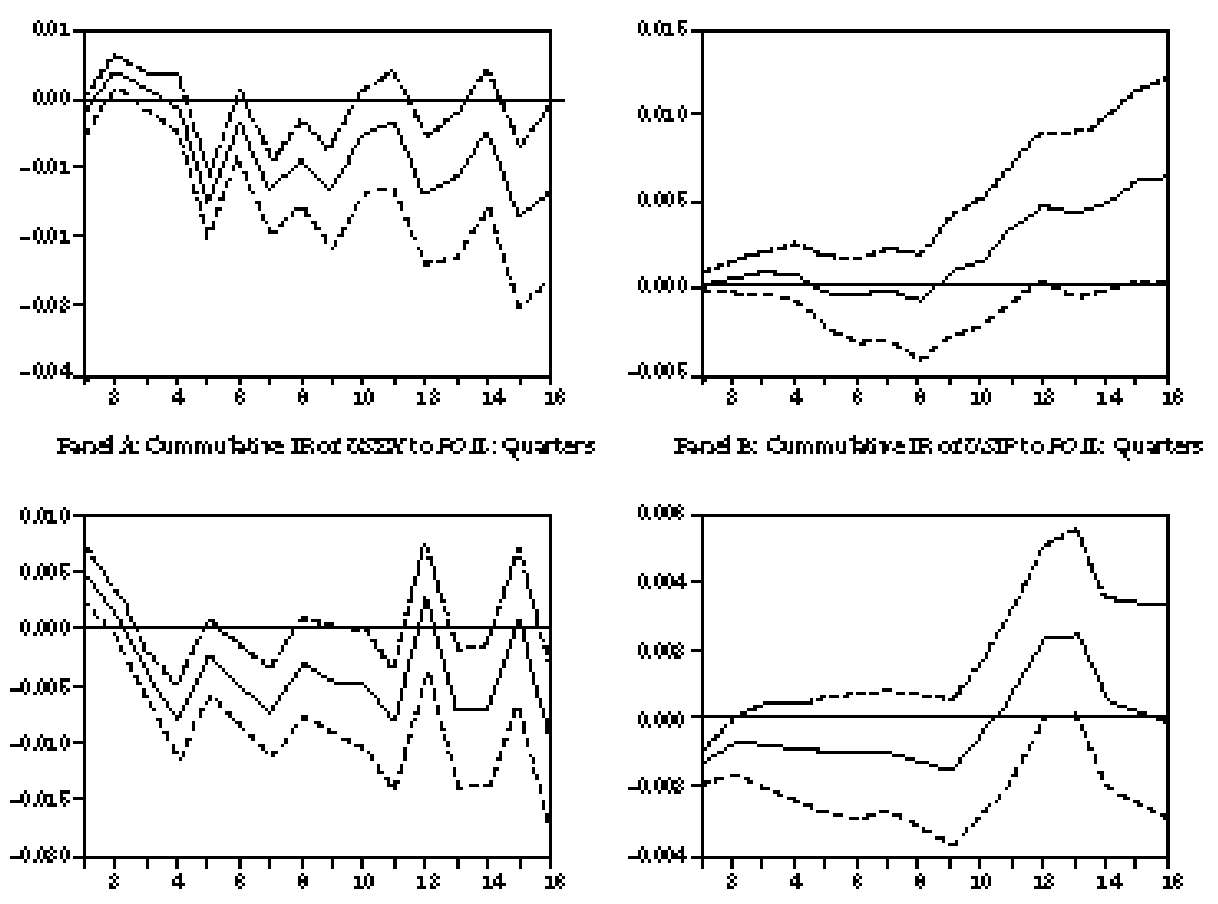

Ford co cummutive IR $\alpha$ USEX bo GFW: Quarters

Fond D: BummuktikeIRot zosf to GPUT: Quviters
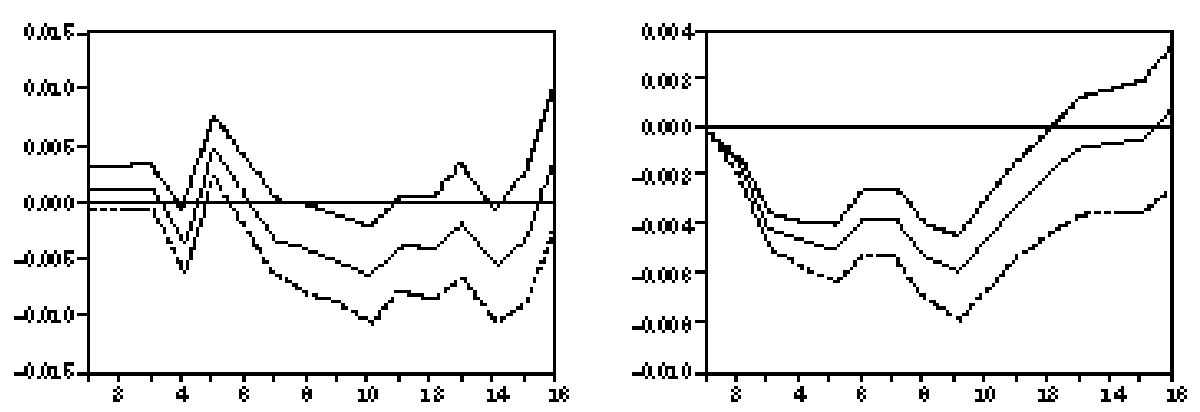


\section{Figure 3}

\section{Impulse Responses of USEX and USIP}
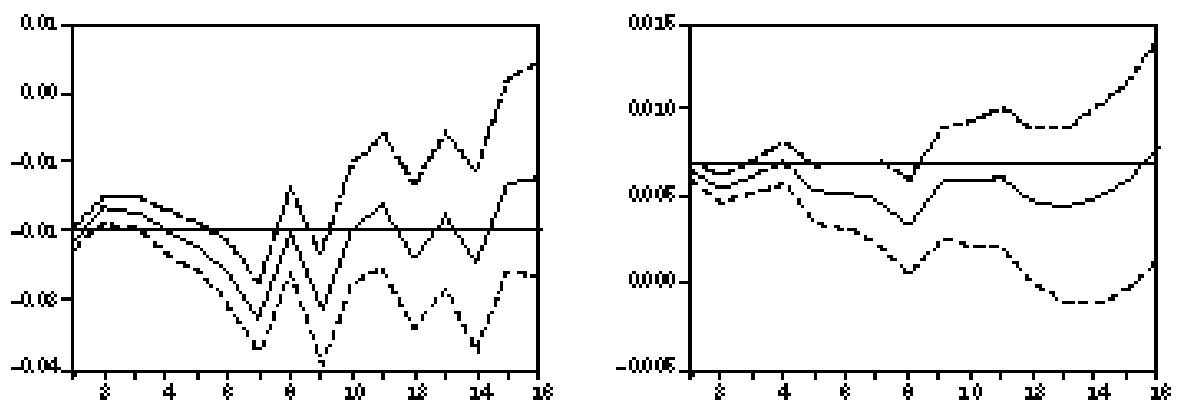

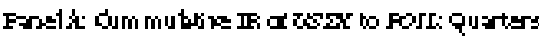

FonstR: CummuthreIR orUSIF to Fo II: Quarters
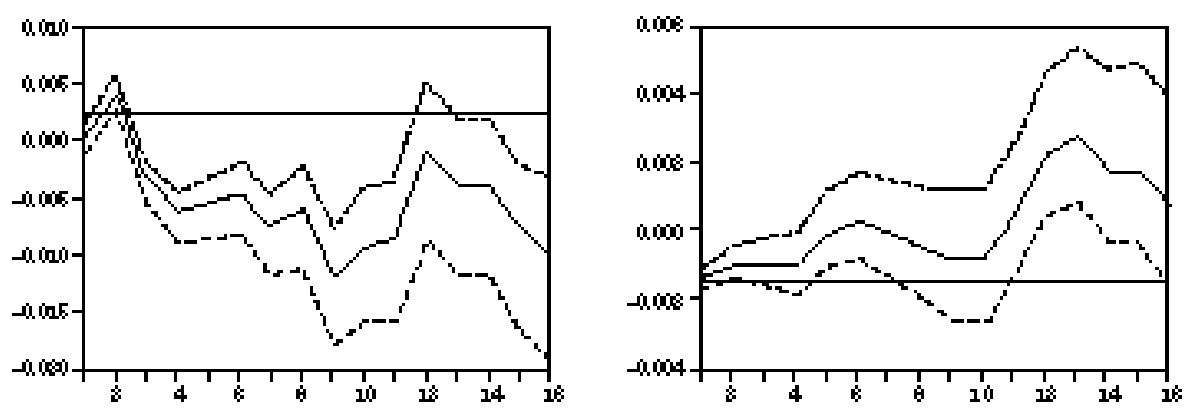

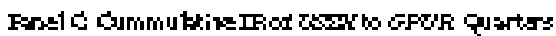

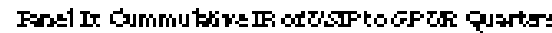
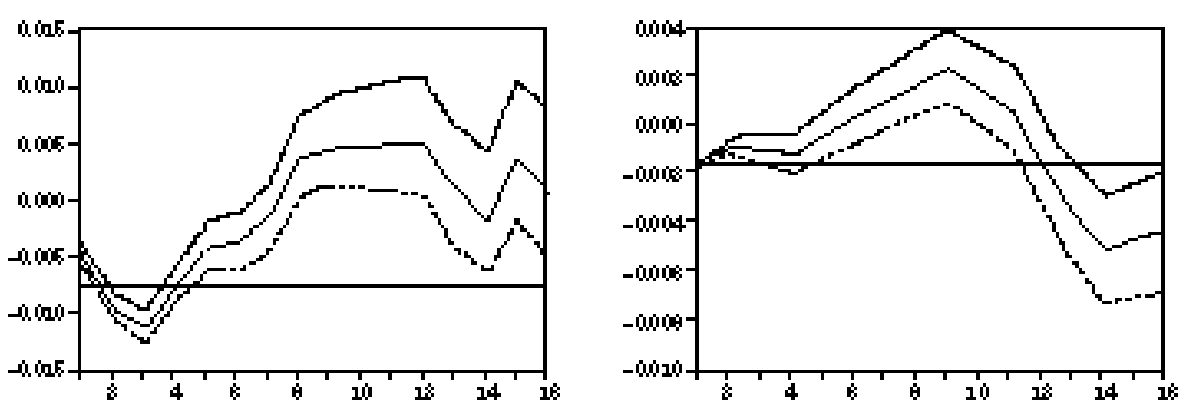

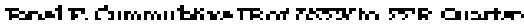

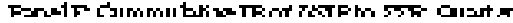




\section{Figure 4}

Impulse Responses Based on 7- and 8-Variable Models
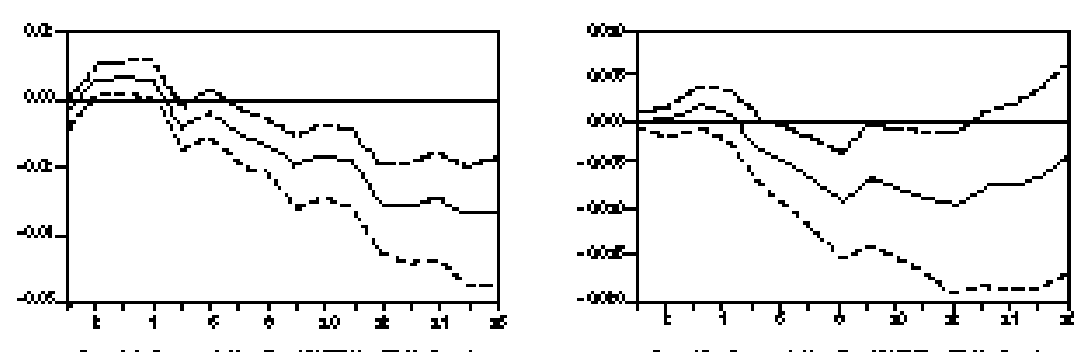

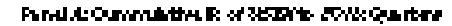

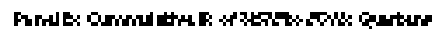
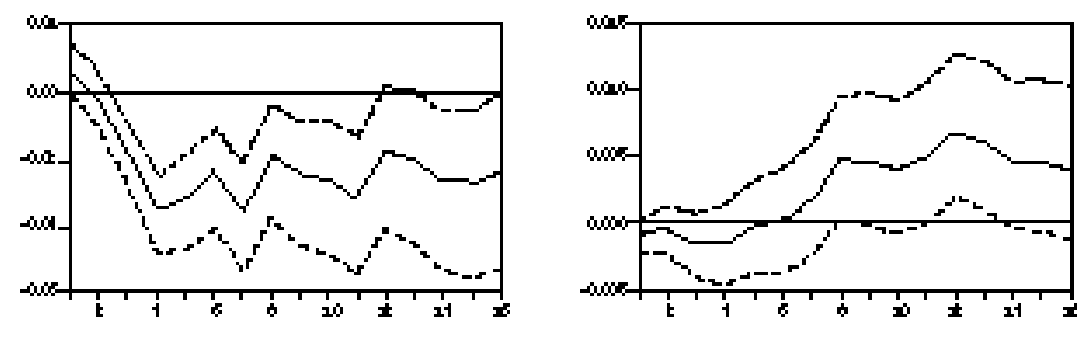

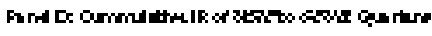
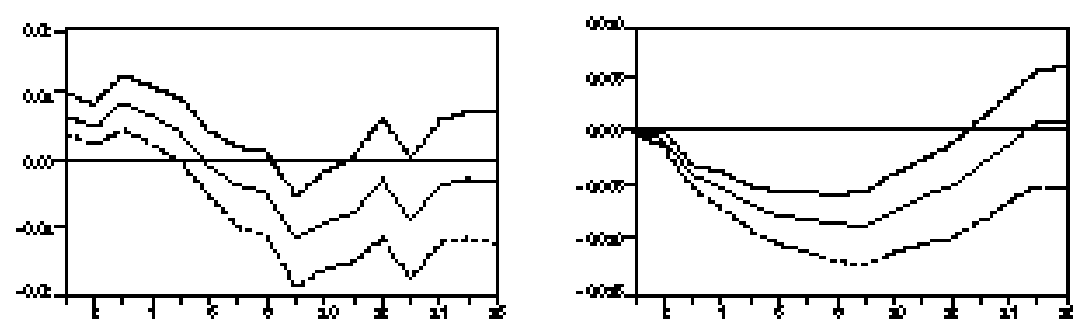

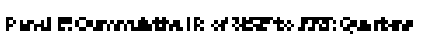
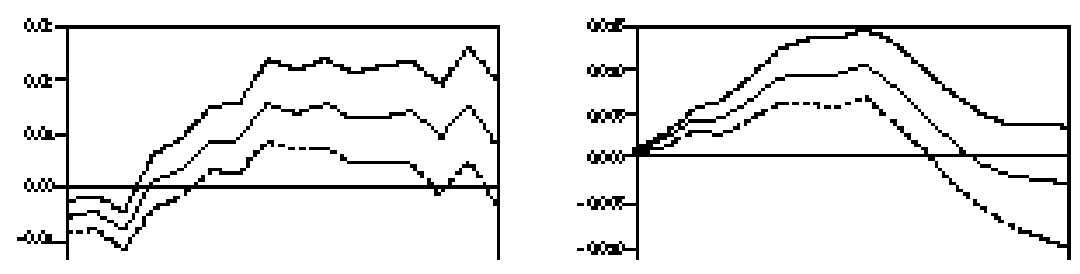
lead to a negative correlation between USEX and USIP. We also examined this relationship within a seven-variable model comprised of GPUR, USIP, PPIUS, USEX, WEA, PWEX, and PUEX. These results (reported in panels $C$ and $D$ of Figure 4 ) are strongly supportive of the conclusion that fluctuations in aggregate economic activity generated by shocks to GPUR lead to a negative correlation between USEX and USIP.

Examination of panel $E$ of $F$ igure 2 indicates that an unanticipated monetary contraction (i.e. a one standard deviation shock to FFR) induces significantly negative responses from USEX for most horizons after the shock. In panel $F$, the unanticipated monetary contraction immediately reduces industrial production and has significantly negative effects on USIP lasting up to three years after the shock. We also examined the impulse responses of USEX and USIP to a FFR shock with an eight-variable model comprised of USIP, PPIUS, PCOM, FFR, USEX, WEA, PWEX, and PUEX. These results (reported in panels $E$ and $F$ of $F$ igure 4 ) are very supportive of the conclusion that business cycle fluctuations initiated by contractionary monetary policy shocks lead to a positive correlation between USEX and USIP.

To evaluate the effects of an unanticipated monetary expansion we used Model II to calculate the impulse responses of USEX and USIP to a one standard deviation shock to NBR. The results are reported in panels $E$ and $F$ of Figure 3 and show that an unanticipated monetary expansion leads, with the exception of a brief period during which exports fall while output rises, to a clearly positive relationship between USEX and USIP. We also examined the impulse responses of USEX and USIP within an eight-variable model with the variables ordered as: USIP, PPIUS, TR, NBR, USEX, WEA, PWEX, and PUEX. The results reported in panels $G$ and $H$ of Figure 4 do not indicate any material departures from those based on the ten-variable 
the method used to identify exogenous monetary policy.

\section{Anomaly or Plausible Result? A Conjecture}

Under the presumption that an unanticipated monetary contraction affects the economy primarily via its effects on aggregate demand, the capacity pressure hypothesis $(\mathrm{CPH})$ suggests that it reduces the pressure on capacity and allows firms to engage in low cost recommitment of excess capacity to the export sector. Consequently, an unexpected monetary contraction leads to falling domestic activity and rising export volume. Given this relatively narrow interpretation of the $\mathrm{CPH}$, the empirical result that monetary shocks lead to a positive correlation between the responses of USIP and USEX appears to be anomalous. Since this apparently anomalous result is robust to model size and to the method employed to identify exogenous monetary policy, we consider the conditions under which both contractionary and expansionary monetary policy shocks are likely to lead to a positive cor relation between USEX and USIP. However, in the absence of a fully specified theoretical model, the opinions we express below are intended to be conjectures that appear to be consistent with our empirical results. Given that monetary policy shocks affect the economy primarily through their effects on aggregate demand, an unanticipated monetary contraction (i.e. a FFR shock in M odel I) increases excess capacity. However, if a substantial fraction of exporting firms are only able to obtain external funds at significantly higher costs than the costs of internal funds, the reductions in cash flow and profits that are typically associated with a monetary contraction will increase their reliance on more costly external funds. ${ }^{18} \mathrm{M}$ oreover, since monetary contractions are typically accompanied by tighter credit conditions and rising open market interest rates, the increased reliance on 
ply of exports at the same time that domestic demand conditions reduce their domestic sales. ${ }^{19}$

Similarly, an unanticipated monetary expansion, (represented by a one standard deviation shock to NBR in Model II) increases the pressure on capacity and would ordinarily lead firms to cut back on export activity. However, if a substantial fraction of exporting firms operate under the financing constraints described above, the opposite effect seems likely. In particular, the unanticipated monetary expansion increases cash flow and profits, reduces open market interest rates and the premium on external finance, while simultaneously increasing credit availability. In sum, these effects lead to substantial increases in exporting firms' financial capacity, a reduction in the costs of committing additional resources to the export sector, and thereby, to increases in both domestic output and export volume.

To assess the plausibility of the assertion that monetary policy shocks have important effects on the costs of recommitting resources to the export sector, we explore the consistency of this interpretation with our results on the responses of USEX and USIP to POIL and GPUR shocks. The effects of a given exogenous shock on excess capacity, depends on whether it affects the economy primarily via aggregate supply or primarily via aggregate demand. For example, if an adverse shock affects the real economy primarily via its effect on aggregate demand, excess capacity increases. On the other hand, if an adverse shock affects the real economy primarily via its effects on aggregate supply, excess capacity should fall. However, as is well illustrated by Hamilton's [1996b] discussion of the mechanism via which oil price increases affect the real economy, increases in the relative price of oil affect the economy through their effects on both aggregate demand and aggregate supply. For our current purposes this implies that it is difficult to determine whether a POIL shock increases or decreases excess capacity. 
tion that oil price shocks affect the real economy primarily via aggregate demand and under the alternative assumption that its effects operate primarily via aggregate supply.

To the extent that an increase in the relative price of oil affects the economy primarily via its effects on aggregate supply, a POIL shock reduces excess capacity. If the shock does not affect the costs of recommitting resources to the export sector, export volume would also fall. Since the effect on output would also be negative, the implied correlation between USEX and USIP would be positive. If the POIL shock also increases open market interest rates and reduces cash flow and profits it would also impair financial capacity and thereby magnify the effects described above. Consequently, the empirical observation that a shock to POIL shock generates a positive correlation between USEX and USIP is consistent with the view that POIL shocks affect the real economy primarily through their effects on aggregate supply. In addition, it is not inconsistent with the conjecture that increases in the relative price of oil exert important effects on the costs of recommitting resources to the export sector by affecting the financial capacity of exporting firms.

On the other hand, if an increase in the relative price of oil exerts most of its effects on the real economy via its effects on aggregate demand, excess capacity would increase and output would fall. Additionally, if the shock has negligible effects on the costs of recommitting resources to the export sector, firms would recommit resources to the export sector so that export volume would rise. However, if the increase in the relative price of oil increases exporting firms' reliance on relatively expensive external funds and decreases credit availability by inducing a "flight to quality", firms' financial capacity and therefore access to operating capital will be severely constricted. Under these circumstances exporting firms will be forced to reduce 
ture, shocks to GPUR are expected to have important supply side effects in the long-run. However, in the short-run GPUR shocks affect the real economy primarily via aggregate demand. Since we are primarily concerned with the cyclical or short-run effects, we deemed it appropriate to assume that GPUR shocks affect the real economy primarily via aggregate demand. Under the preceding assumption, an increase in GPUR leads to a decrease in excess capacity. If the GPUR shock has negligible effects on the costs of recommitment, export volume falls and given that output rises, there is a negative correlation between USEX and USIP. On the other hand if the GPUR shock had important or material effects on financial capacity we would expect the improvement in financial conditions to allow firms to increase both foreign and domestic sales so that both USEX and USIP would rise. Therefore, our results are consistent with the view that in the short-run an increase in real government purchases affects the economy primarily via aggregate demand and that it does not have material effects on financial capacity and the costs of recommitting resources to and from the export sector.

A relatively modest and perhaps secondary goal of stabilization policy may be to attenuate the business cycle behavior of export volume. Our results suggest that a recession that is precipitated by tight monetary policy or by unanticipated increases in the relative price of oil will be characterized by falling exports. If policy makers respond by increasing the supply of money, both output and export volume will rise. However, if policy makers respond by increasing real government purchases, export volume would fall even further but output rises. Therefore, if a secondary objective of fiscal and monetary policies is to encourage export volume, our results clearly suggest that monetary expansion should be the preferred policy response to cyclically declining economic activity. 
which the shock in question affects the real economy. For example, if an adverse shock affects aggregate economic activity primarily via its effect on aggregate supply, the resulting decline in USIP would indicate an increase in the pressure on capacity (i.e. a decrease in excess capacity). However, if the adverse shock affects the macroeconomy by reducing aggregate demand, the resulting fall in USIP should be associated with a decrease in the pressure on capacity (i.e. an increase in excess capacity). Consequently, in the absence of further information about the channel via which a shock affects the aggregate economy, a movement in USIP that should be linked to an increase in excess capacity may be obser vationally equivalent to a movement that should be linked to a decrease in excess capacity. Since our empirical model does not allow us to econometrically identify the precise channel(s) via which a shock affects the real economy, we have relied on theoretical arguments in the cases of monetary policy shocks and GPUR shocks to argue that they affect the economy primarily via aggregate demand. In the case of oil price shocks we refrained from making any such assumption because of our perception that there is a lack of theoretical and empirical consensus on exactly how oil price shocks affect the real economy.

The capacity pressure hypothesis is most frequently characterized as the assertion that an increase in excess capacity of whatever origin allows firms to recommit resources to the export sector at relatively low cost. As a result, export volume increases. Viewed in this narrow light, if oil price shocks affect the economy primarily via their effects on aggregate supply, the decrease in USIP associated with an unanticipated increase in the relative price of oil indicates a reduction in excess capacity. Since this naivve version of the $\mathrm{CPH}$ suggests that export volume falls when capacity pressure increases our results may be deemed consistent with the $\mathrm{CPH}$ subject to the accuracy of the assumption that oil price shocks affect the real economy pri- 
since monetary shocks are widely believed to affect the aggregate economy via their effects on aggregate demand, the decrease (increase) in USIP associated with an unanticipated monetary contraction (expansion) is interpreted as indicating an increase (decrease) in excess capacity. Since the naïve version of the $\mathrm{CPH}$ suggests that export volume falls (rises) when capacity pressure increases (decreases) our results are not consistent with the naïve version of the $\mathrm{CPH}$.

The inconsistency described above encouraged us to consider a broader interpretation of the $\mathrm{CPH}$ that allows for the possibility that the exogenous shocks that cause changes in capacity pressure and generate co-movements between USEX and USIP also affect the costs of recommitting resources to the export sector. We find that all of our results are consistent with this broader interpretation of the $\mathrm{CPH}$. In particular, while an unanticipated monetary contraction (expansion) decreases (increases) the pressure on capacity, export volume falls (rises) because the monetary contraction (expansion) increases (decreases) the costs of committing resources to the export sector. Consequently, the observation that monetary shocks (both contractionary and expansionary) lead to a positive correlation between USEX and USIP is not inconsistent with our broader interpretation of the capacity pressure hypothesis.

For many economists, monetary and/ or oil price shocks are responsible for initiating most of the major fluctuations in aggregate economic activity in the postwar period. To the extent that this assessment is accurate, our results suggests that far from being anomalous, the "provocative" conclusions of Dunlevy and of Haynes and Stone [1983] that there is a procyclical relation between their measures of capacity pressure and export performance is exactly the result one would expect to find. In particular, the D unlevy and Haynes-Stone results is merely a reflection of the type of shocks 
tic economic activity. In contrast to the preceding literature, our empirical models explicitly recognize the potential importance of both policy and nonpolicy shocks as important initiators of business cycle fluctuations and of variation in export volume. The empirical regularities we uncovered suggest that the relationship between business cycle fluctuations and export performance is dependent upon the type of shock that initiates movements in aggregate activity. If the initiating shock is an increase in the relative price of oil or a monetary shock (either contractionary or expansionary), the resulting cor relation between export performance and domestic activity is positive. On the other hand, if the initiating shock is a change in government purchases, the cor relation is negative.

These results are fully consistent with a broad interpretation of the $\mathrm{CPH}$ that allows for the possibility that monetary and other shocks have important effects on the costs of committing resources to the export sector. Overall, our results suggest that the procyclical capacity pressure effect reported in the Dunlevy and Haynes-Stone studies merely reflects the importance of oil price and monetary shocks during their sample periods. Finally, the consistency of our empirical results with the conjecture that monetary and oil price shocks have important effects on the costs of recommitting resources to the export sector highlight the need for further research on the precise mechanism(s) via which any such effects are exerted.

\section{References}

Artus, Jacques R. [1970], "The Short-run Effects of Domestic Demand Pressure on British Export Performance," IM F Staff Papers 17; pp. 247-274.

Artus, Jacques R. [1973], "The Short-run Effects of Demand Pressure on Export Delivery Delays for M achiner $y, "$ Journal of International E co - 
nal of E conomic Perspectives 3; pp. 37-54.

Bernanke, Ben, S., and A.S. Blinder [1992], "The Federal Funds Rate and the Channels of M onetary Policy," American Economic Review 82; pp. 901-921.

Bernanke, Ben, S., and M. Gertler [1995], "Inside the Black Box: The Credit Channel of Monetary Policy Transmission," Journal of Economic Perspectives 9; pp. 27-48.

Bernanke, Ben, S., and I. M ihov [1995], "M easuring M onetary Policy," NBER Working Paper \#5145.

Bernanke, Ben, S., M. Gertler, and M. Watson [1997], "Systematic M onetary Policy and the Effects of Oil Price Shocks," Brookings Papers on E conomic Activity 1; pp. 91-157.

Brock, Philip L. [1991], "Export Instability and the E conomic Performance of Developing Countries," Journal of E conomic Dynamics and Control 15; pp. 129-147.

Christiano, Lawrence, J., M. Eichenbaum, and C. L. Evans [1996], "The Effects of M onetary Policy Shocks: Evidence from the Flow of Funds," The Review of E conomics and Statistics 78; pp. 16-34.

Christiano, Lawrence, J., M. Eichenbaum, and C. L. Evans [1997], "Sticky Price and Limited Participation M odels of M oney: A Comparison," European Economic Review 41; pp. 1201-1249.

Culem, Claudy, G. [1987], “Foreign Trade Behavior in a Small Open Economy: Belgium 1970-1980," Scandinavian Journal of Economics 89; pp. 55-70.

Cushman, David O. [ 1987], "Bilateral Trade Balances and the Dollar," Eco nomic Letters 24; pp. 363-367.

Cushman, David, O., and Zha, Tao [1997], "I dentifying M onetary Policy in a Small Open Economy under Flexible Exchange Rates," Journal of 


\section{VAR E conometrics}

Dotsey, M ., and M. Reid [1992], "Oil Shocks, M onetary Policy, and Economic Activity," Federal Reserve Bank of Richmond, Economic Review (J uly/ August 1992); pp. 14-27.

Dunlevy, James A. [1980], "A Test of the Capacity Pressure Hypothesis within a Simultaneous Equations Model of Export Performance," The Review of E conomics and Statistics 62; pp. 131-135.

Engle, Robert F., and Byung Sam Yoo [1987], "Forecasting and Testing in Co-integrated Systems," J ournal of E conometrics 35; pp. 143-159.

Faini, Riccardo [1994], “Export Supply, Capacity, and Relative Prices," Jour nal of Development E conomics 45; pp. 81-100.

Goldstein, M orris, and M oshin S. Khan [1985], "Income and Price E ffects in Foreign Trade," in R. W. Jones and P. B. Kenen, eds.: Handbook of International Economics, Vol. II, (North Holland, Amsterdam, Holland)

Gordon, David, B., and Eric M. Leeper [1994], "The Dynamic Impacts of M onetary Policy: An Exercise in Tentative Identification," Journal of Political Economy 102; pp. 1228-1247.

Hamilton, James, D. [1983], "Oil and the M acroeconomy Since World War II," Journal of Political E conomy 91; pp. 228-248.

Hamilton, James, D. [1988], “A Neoclassical M odel of Unemployment and the Business Cycle," Journal of Political E conomy 96; pp. 593-617.

Hamilton, James, D. [1996a], "This is What Happened to the Oil PriceM acroeconomy E elationship," Journal of M onetary E conomics 38; pp. 215-220.

Hamilton, James, D. [1996b], "Analysis of the Transmission of Oil Price Shocks through the M acroeconomy," Unpublished Paper, University of California, San Diego. 
Lutkephol, H. [1982], "Noncausality Due to Omitted Variables," Journal of E conometrics 19; pp. 367-78.

M intz, Ilse [1961], "American Exports During Business Cycles," 1879-1958, NBER Occasional Paper 76, New York, 1961.

M intz, Ilse [1967], Cyclical Fluctuations in the Exports of the United States Since 1879, N ew York: Columbia University Press for the National Bureau of Economic Research.

Mork, K. A. [1989], "Oil and the M acroeconomy When Prices Go up and Down: An Extension of Hamilton's Eesults," Journal of Political E cono my 97; pp. 740-744.

M urray, Tracy and Peter, J. Ginman [1976], "An E mpirical Examination of the Traditional Aggregate Import Demand M odel," Review of E conom ics and Statistics 58; pp. 75-80.

Sims, Christopher, A. [ 1992], "Interpreting the Macroeconomic Time Series Facts: The E ffects of M onetary Policy," E uropean E conomic Review 36; pp. 975-1011.

Strongin, Steven [1995], "The Identification of M onetary Policy Disturbances: Explaining the Liquidity Puzzle," J ournal of M onetary E conom ics 35; pp. 463-497.

Uhm, Ihn H., and Won W. Koo [1990], "Effects of the Canadian-U nited States Free Trade Agreement on Bilateral Flows of Agricultural and Industrial Products," Canadian Journal of Agricultural Economics 38; pp. $991-1004$.

Winters, L. Allan [1974], "United Kingdom Exports and the Pressure of Demand: A N ote," Economic Journal 84; pp. 623-628. 